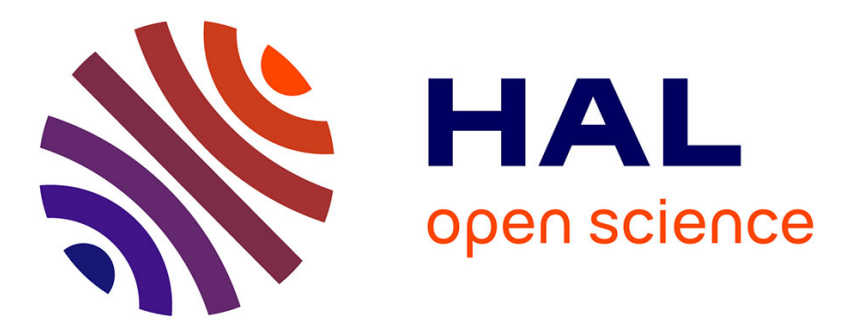

\title{
Interactions between beta-lactoglobulin and aroma compounds: Different binding behaviors as a function of ligand structure
}

\author{
Laurette Tavel, Isabelle Andriot, Céline Moreau, Elisabeth Guichard
}

\section{- To cite this version:}

Laurette Tavel, Isabelle Andriot, Céline Moreau, Elisabeth Guichard. Interactions between betalactoglobulin and aroma compounds: Different binding behaviors as a function of ligand structure. Journal of Agricultural and Food Chemistry, 2008, 56 (21), pp.10208-10217. 10.1021/jf801841u . hal-01413538

\author{
HAL Id: hal-01413538 \\ https://hal.science/hal-01413538
}

Submitted on 9 Dec 2016

HAL is a multi-disciplinary open access archive for the deposit and dissemination of scientific research documents, whether they are published or not. The documents may come from teaching and research institutions in France or abroad, or from public or private research centers.
L'archive ouverte pluridisciplinaire HAL, est destinée au dépôt et à la diffusion de documents scientifiques de niveau recherche, publiés ou non, émanant des établissements d'enseignement et de recherche français ou étrangers, des laboratoires publics ou privés. 


\section{Article}

Interactions between \#-Lactoglobulin and Aroma Compounds: Different Binding Behaviors as a Function of Ligand Structure

Laurette Tavel, Isabelle Andriot, Ce\#line Moreau, and Elisabeth Guichard J. Agric. Food Chem., 2008, 56 (21), 10208-10217 • DOI: 10.1021/jf801841u • Publication Date (Web): 18 October 2008

Downloaded from http://pubs.acs.org on November 26, 2008

\section{More About This Article}

Additional resources and features associated with this article are available within the HTML version:

- $\quad$ Supporting Information

- $\quad$ Access to high resolution figures

- $\quad$ Links to articles and content related to this article

- Copyright permission to reproduce figures and/or text from this article

\section{View the Full Text HTML}




\title{
Interactions between $\beta$-Lactoglobulin and Aroma Compounds: Different Binding Behaviors as a Function of Ligand Structure
}

\author{
Laurette Tavel, Isabelle Andriot, Céline Moreau, and \\ ELISABETH GUICHARD* \\ INRA, UMR 1129 FLAVIC, F-21000 Dijon, France; ENESAD, UMR 1129 FLAVIC, \\ F-21000 Dijon, France; and Université de Bourgogne, UMR 1129 FLAVIC, F-21000 Dijon, France
}

\begin{abstract}
Interactions between $\beta$-lactoglobulin (BLG) in its monomeric form and a wide range of aroma compounds were investigated by Fourier transform infrared (FT-IR) and 2D nuclear magnetic resonance (NMR) spectroscopies. A screening of the ligands was carried out by FT-IR through the amide I region changes of BLG upon binding. The location of two binding sites was determined by 2D NMR from the study of 10 selected ligands with different structures. All of the data suggest at least two binding behaviors as a function of the chemical class, the hydrophobicity, or the structure of the ligands. The binding of the elongated aroma compounds, such as 2-nonanone or ethyl pentanoate, within the central cavity involves residues located at the entrance of the calyx and Trp19. The binding onto the protein surface of aroma compounds that have or adopt a compact structure occurs in a site located between strand $\beta$-G, $\alpha$ helix, and strand $\beta$-I.
\end{abstract}

KEYWORDS: $\beta$-Lactoglobulin; aroma compound; protein-ligand interactions; binding sites location; FTIR; 2D NMR

\section{INTRODUCTION}

Control of the organoleptic properties of food requires an understanding of the binding mechanisms between aroma compounds and all of the constituents present in the medium $(1,2)$. More specifically, the binding of aroma compounds to protein is known to reduce the quantity of free aroma compounds available for release and, then, perception. In this context, the major whey protein, $\beta$-lactoglobulin (BLG), found in a variety of foods and belonging to the lipocalin family, has been used widely as a simple model.

BLG is a globular protein (18.3 kDa) composed of 162 amino acids. Its structural characterization has been reported by nuclear magnetic resonance (NMR) spectroscopy at acidic $\mathrm{pH}$, where the protein exists in its monomeric form (3-6), and by X-ray crystallography at around neutral $\mathrm{pH}$, where a dimeric structure is observed (7-9). Jameson et al. compared the structures of bovine BLG depending on the experimental techniques (NMR or X-ray) used, protein variant, $\mathrm{pH}$, crystal form, and ligand nature (10). The authors showed the same general structure for bovine BLG under the various conditions. As depicted in Figure $\mathbf{1}$, the secondary structure of BLG at $\mathrm{pH} 2.6$ is composed of eight antiparallel $\beta$ strands, labeled $\beta$-A to $\beta$ - $\mathrm{H}$, folded with an up-down-up-down topology to form a central calyx. Attached to the calyx is a three-turn $\alpha$ helix (residues 129-142), which

* Author to whom correspondence should be addressed (telephone +33 3806932 77; fax +33 3806932 27; e-mail guichard@ dijon.inra.fr). is followed by an extra $\beta$ strand, $\beta$-I (residues $145-150$ ). The same core structure remains whatever the $\mathrm{pH}$ considered. However, the protein structure at acidic $\mathrm{pH}$ is characterized by the presence of disordered loops and terminal regions (3). A deeper comparison of the $\mathrm{X}$-ray structure at neutral $\mathrm{pH}$ with the NMR structure at $\mathrm{pH} 2.6$ reveals that lowering the $\mathrm{pH}$ led to the disruption of a salt bridge between the side chain of Glu74 (strand $\beta$-D) and Lys83 (strand $\beta$-E) and then softened the structure of the protein near the entrance of the calyx. In addition, the loop EF (residues 85-90) may act as a gate over the central calyx. It is folded over the entrance of the calyx (closed conformation) at $\mathrm{pH} 2.6$ or 6.2 , or conversely, folded

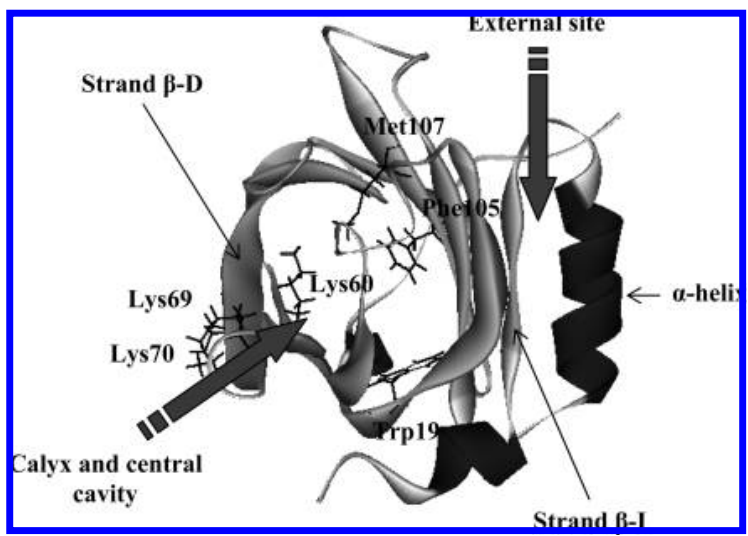

Figure 1. Secondary structure of $\mathrm{BLG}$ at pH 2.6 obtained from PDB (one structure from 1dv9) deposited by Uhrinova et al. (5). 
back (open conformation) to reveal the interior of the calyx at pH 7.1 or $8.2(5,7-9)$. The secondary structure of BLG is arranged as at least two hydrophobic binding sites as shown in Figure 1: one internal site, the central cavity, within the hydrophobic calyx, and one external site on the outer surface of BLG in a groove between $\beta$ strands and $\alpha$ helix. From NOE NMR experiments, the internal binding site has been described precisely for BLG at $\mathrm{pH}$ 2.0. It consists of a small buried cluster composed of 11 hydrophobic residues centered on residue Trp19 (6). Other studies were conducted by NMR for BLG in solution at $\mathrm{pH} 2.0$ (6) and by X-ray diffraction methods at $\mathrm{pH} 7.5$ (11). They showed the existence of a second external site, that is, a hydrophobic surface pocket in a groove between the $\beta$ strands and $\alpha$ helix.

Because its structure was well-characterized, BLG has been used widely as a simple model in numerous studies to investigate further the mechanisms governing retention/release mechanisms of aroma compounds in foods. These retention/release mechanisms of aroma compounds were studied using chromatographic techniques, equilibrium dialysis, or static headspace (12). Information on the percentage of retention, the global affinity, and the binding constants was thus provided. It was demonstrated that BLG has an impact on retention/release of a wide range of aroma compounds, such as aldehydes, ketones, esters, alcohols, and pyrazines, depending on the protein concentration, the medium conditions ( $\mathrm{pH}$, ionic strength, etc.), and the nature of aroma compound (13-17). Moreover, within the same chemical class, aroma compounds with longer chain lengths bind more strongly to BLG, suggesting hydrophobic interaction phenomenon. Other works focused on the determination of binding site location of hydrophobic ligands on BLG. Fluorescence and X-ray studies highlighted the role of Lys60, Lys69, and Lys70 located at the entrance of the calyx in the central cavity binding at around neutral $\mathrm{pH}(18-20)$. The binding of $\beta$-ionone, retinol, and fatty acid lactones was reported in the vicinity of residue Trp19 buried in the calyx by fluorescence at pH 3 and $7(21,22)$. NMR study showed that palmitate is bound within the central cavity of BLG at pH 7.3 (23). Nevertheless, despite numerous studies, the use of various experimental conditions and techniques makes difficult data comparisons explaining the controversial results obtained on ligand binding site(s), as, for instance, observed in the case of retinol. The binding of retinol onto the surface pocket of BLG was shown by X-ray at $\mathrm{pH} 7.5$ (11) and by fluorescence at $\mathrm{pH} 7.1$ (in 50 $\mathrm{mM}$ Tris buffer) (24). In contrast, its binding within the central cavity of BLG was evidenced by X-ray at pH 7.5 (25), by Trp fluorescence at $\mathrm{pH} 8.0$ (in $50 \mathrm{mM}$ potassium phosphate buffer) (18), by a modeling study from the crystal structure of BLG at around neutral $\mathrm{pH}(19)$, and by retinol fluorescence at $\mathrm{pH}$ 2.5-10.5 (in 0.01 M phosphate buffer) (26).

To highlight the influence of the aroma compound structure on ligand binding, we investigated binding behaviors of a wide range of aroma compounds with one protein variant (BLG variant $\mathrm{A}$ ) under similar acidic $\mathrm{pH}$ conditions by using Fourier transform infrared (FT-IR) and NMR spectroscopies. Infrared spectroscopy is a technique of choice complementary to the high-resolution NMR technique. Characteristic bands found in the IR spectra of proteins include the amide I band (1700$1600 \mathrm{~cm}^{-1}$ ), which arises from the amide bonds that link the amino acids and provides information about the secondary structure of proteins. FT-IR experiments allowed us to screen 27 aroma compounds, belonging to different chemical classes, through changes of spectra in the amide I band. The discrimination was deduced from the distribution of the ligands in the plane of the principal component analysis (PCA) depicting the amide I region changes of BLG upon addition of one aroma compound. Ten ligands with different structures were selected from FT-IR data. The key amino acid residues of BLG that are involved in the ligand binding were highlighted by 2D NMR spectroscopy for the two sites of the monomeric BLG. The FTIR discrimination combined with the location of binding sites by NMR allowed us to establish a relationship between the ligand structure and their binding behaviors. The aim of the present study is to give new insights into the binding mechanisms providing to the food industry some clues to control the retention and then the release of aroma compounds from dairy products.

\section{MATERIALS AND METHODS}

Chemicals. Bovine milk BLG variant A (lot L7880, purity $\geq 90 \%$ ) and all of the aroma compounds were purchased from Sigma-Aldrich. Physicochemical characteristics of aroma compounds are shown in Table 1.

Sample Preparation. The conditions used in terms of $\mathrm{pH}$, ionic strength, and protein concentration were chosen to ensure that BLG is present in a native monomeric state. BLG was used without further purification and dissolved in two different solvents. Solvent A, 5\% ethanol/50 mM phosphate buffer, $\mathrm{pH} 2.00( \pm 0.05)$, was used for FTIR experiments. Solvent B, $12 \mathrm{mM} \mathrm{NaCl} \mathrm{pH}$ adjusted to $\mathrm{pH} 2.35$ $( \pm 0.15)$ with $0.1 \mathrm{~N} \mathrm{HCl}$, was used for NMR analyses. BLG-aroma compound solutions were prepared in an identical manner, with the addition of one aroma compound to the protein solution at least $2 \mathrm{~h}$ before NMR analysis and one night at room temperature in a dark flask for FT-IR analysis. Final concentrations of BLG and aroma compounds used for FT-IR and NMR experiments are listed in Table 1. The solubility of ligands and their affinity constants for BLG $\left(K_{\mathrm{B}}\right.$ values) previously measured by affinity chromatography $(15,16,27)$ was taken into account to determine our experimental conditions. The concentrations of aroma compounds were chosen to reach at least a ratio of complexed protein $(\alpha)$ equal to $50 \%$. The concentration of ligand was calculated with the following equation for $C_{\mathrm{BLG}} \neq C_{\text {ligand }}$ such as $C_{\mathrm{BLG}}=x K_{\mathrm{D}}$ and $C_{\text {ligand }}=y K_{\mathrm{D}}$ :

$$
\alpha=\frac{(x+y+1)-\sqrt{(x+y+1)^{2}-4 x y}}{2 x}
$$

with $K_{\mathrm{D}}$ the dissociation constant of the ligand $\left(K_{\mathrm{D}}=1 / K_{\mathrm{B}}\right)$.

Control aroma compound solutions were prepared by diluting the ligands in both solvents at concentrations equivalent to the corresponding BLG-aroma compound solutions.

FT-IR Experiments. The samples in solvent A were used for FTIR experiments. Ethanol (5\% v/v) was used to increase the solubility of aroma compounds, because a high BLG/aroma compound ratio was required to observe an impact of aroma compound addition on the protein spectrum. FT-IR experiments were achieved for the 27 aroma compounds listed in Table 1. Infrared spectra were obtained with a FTS6000 FT-IR (Bio-Rad) spectrometer, equipped with a horizontal ATR flow-through accessory (internal volume $=350 \mu \mathrm{L}$, Harrick Scientific Co). The infrared spectra were co-added with 512 scans at a resolution of $2 \mathrm{~cm}^{-1}$. The spectra of protein alone, aroma compound alone, and protein/aroma compound solutions were collected in duplicate. The spectra of aroma compound solutions were subtracted from spectra of protein/aroma compound solutions (spectrum a); water vapor was then subtracted from spectrum a. The subtraction factors were chosen so that the amide I/amide II area ratio was 1.92 (28). A spectral smoothing (Savitsky-Golay algorithm, 15 points) and a baseline correction were also applied. A normalization of spectrum a was done with regard to the amide I area $\left(1700-1590 \mathrm{~cm}^{-1}\right)$. Differential spectra in the amide I band of BLG were the results of the mean of the subtraction of the FT-IR spectra of protein solutions (Figure 2a) from spectrum a. The standard deviations were calculated with the 16 differential spectra obtained for a given aroma compound (subtraction of the 2 replicates of solvent spectra from the 2 replicates of protein spectra yields 4 solvent subtracted spectra; subtraction of the 4 spectra of protein alone from the spectra of protein with aroma 
Table 1. Physicochemical Characteristics of Aroma Compounds and Concentrations of Protein and Ligand Used for NMR and FT-IR Experiments ${ }^{a}$

\begin{tabular}{|c|c|c|c|c|c|c|c|c|}
\hline \multirow{3}{*}{$\begin{array}{c}\text { Ligand } \\
\mathrm{MW}\left(\mathrm{g} \cdot \mathrm{mol}^{-1}\right)\end{array}$} & \multirow[t]{3}{*}{ Structure } & \multirow[t]{3}{*}{$\mathrm{K}_{\mathrm{B}}\left(\mathrm{M}^{-1}\right)$} & \multirow[t]{3}{*}{$\log \mathrm{P}$} & \multirow{3}{*}{$\begin{array}{c}\mathrm{S}^{\mathrm{g}} \\
\mathrm{g} \cdot \mathrm{L}^{-1} \\
m M^{*}\end{array}$} & \multicolumn{4}{|c|}{ Concentrations (mM) } \\
\hline & & & & & \multicolumn{2}{|c|}{ NMR } & \multicolumn{2}{|c|}{ FT-IR } \\
\hline & & & & & BLG & Ligand & BLG & Ligand \\
\hline $\begin{array}{c}\text { 2-hexanone } \\
110.16\end{array}$ & & $163^{c}$ & 1.24 & $\begin{array}{c}7.74 \\
70.31\end{array}$ & - & - & 0.25 & 58.10 \\
\hline $\begin{array}{c}\text { 2-heptanone } \\
114.19\end{array}$ & & $645^{\mathrm{c}}$ & 1.73 & $\begin{array}{l}2.14 \\
18.78\end{array}$ & - & - & 0.25 & 24.50 \\
\hline $\begin{array}{c}\text { 2-octanone } \\
128.22\end{array}$ & & $1287^{c}$ & 2.22 & $\begin{array}{l}0.88 \\
6.89\end{array}$ & - & - & 0.25 & 8.00 \\
\hline $\begin{array}{c}\text { 2-nonanone } \\
142.24\end{array}$ & & $3629^{\circ}$ & 2.71 & $\begin{array}{l}0.17 \\
1.19\end{array}$ & $\begin{array}{l}0.33 \\
0.60\end{array}$ & $\begin{array}{l}0.68 \\
0.60\end{array}$ & 0.25 & 3.00 \\
\hline $\begin{array}{c}\text { 2-undecanone } \\
170.3\end{array}$ & & $37153^{\mathrm{e}}$ & 3.69 & $\begin{array}{l}0.02 \\
0.11\end{array}$ & - & - & 0.25 & 0.30 \\
\hline $\begin{array}{c}\alpha \text {-ionone } \\
192.3\end{array}$ & & $13456^{\mathrm{c}}$ & 4.29 & $\begin{array}{l}0.02 \\
0.13\end{array}$ & 0.50 & 0.51 & 0.25 & 1.00 \\
\hline $\begin{array}{c}\beta \text {-ionone } \\
192.3\end{array}$ & & $19143^{\mathrm{c}}$ & 4.42 & $\begin{array}{l}0.02 \\
0.13\end{array}$ & 0.37 & 0.38 & 0.25 & 1.00 \\
\hline $\begin{array}{c}\text { isoamyl acetate } \\
130.18\end{array}$ & & $153^{\mathrm{a}}$ & 2.26 & $\begin{array}{l}1.07 \\
8.22\end{array}$ & 0.80 & 8.00 & 0.25 & 10.80 \\
\hline $\begin{array}{c}\text { ethyl butanoate } \\
116.16\end{array}$ & & $55^{\mathrm{a}}$ & 1.85 & $\begin{array}{c}2.74 \\
23.63\end{array}$ & - & - & 0.25 & 12.00 \\
\hline $\begin{array}{c}\text { ethyl pentanoate } \\
130.19\end{array}$ & & $196^{\mathrm{a}}$ & 2.34 & $\begin{array}{l}0.92 \\
7.11\end{array}$ & 0.65 & 6.50 & 0.25 & 10.80 \\
\hline $\begin{array}{c}\text { ethyl hexanoate } \\
144.21\end{array}$ & & $543^{\mathrm{a}}$ & 2.83 & $\begin{array}{l}0.31 \\
2.14\end{array}$ & - & - & 0.25 & 2.00 \\
\hline $\begin{array}{c}\text { ethyl heptanoate } \\
158.24\end{array}$ & & $1434^{\mathrm{a}}$ & 3.32 & $\begin{array}{l}0.10 \\
0.64\end{array}$ & - & - & 0.25 & 0.60 \\
\hline $\begin{array}{c}\text { linalool } \\
154.25\end{array}$ & & $565^{\mathrm{b}}$ & 3.38 & $\begin{array}{l}0.68 \\
4.43\end{array}$ & 1.50 & 3.00 & 0.25 & 5.20 \\
\hline $\begin{array}{c}\text { nerol } \\
154.25\end{array}$ & & $1134^{\mathrm{b}}$ & 3.47 & $\begin{array}{l}0.25 \\
1.65\end{array}$ & - & - & 0.25 & 3.90 \\
\hline $\begin{array}{l}\text { carveol } \\
152.24\end{array}$ & & $542^{\mathrm{b}}$ & 3.29 & $\begin{array}{l}0.51 \\
3.41\end{array}$ & - & - & 0.25 & 3.90 \\
\hline $\begin{array}{l}\text { carvone } \\
150.22\end{array}$ & & $748^{\mathrm{b}}$ & 3.07 & $\begin{array}{l}1.3 \\
8.66\end{array}$ & 0.50 & 1.80 & 0.25 & 5.90 \\
\hline $\begin{array}{c}\alpha \text {-menthone } \\
154.25\end{array}$ & & $1138^{\mathrm{b}}$ & 2.87 & $\begin{array}{l}0.68 \\
4.46\end{array}$ & - & - & 0.25 & 5.70 \\
\hline $\begin{array}{c}\gamma \text {-decalactone } \\
170.25\end{array}$ & & $3230^{c}$ & 2.57 & $\begin{array}{l}0.29 \\
1.71\end{array}$ & $\begin{array}{c}0.9 \\
1.50\end{array}$ & $\begin{array}{l}1.74 \\
1.55\end{array}$ & 0.25 & 3.30 \\
\hline $\begin{array}{c}\text { p-cresol } \\
108.14\end{array}$ & & $440^{\mathrm{b}}$ & 2.06 & $\begin{array}{l}9.24 \\
85.5\end{array}$ & - & - & 0.25 & 23.00 \\
\hline $\begin{array}{c}\text { 4-ethylphenol } \\
122.17\end{array}$ & & $888^{\mathrm{b}}$ & 2.55 & $\begin{array}{l}2.34 \\
19.2\end{array}$ & - & - & 0.25 & 11.50 \\
\hline $\begin{array}{c}\text { guaiacol } \\
124.1\end{array}$ & & $245^{\mathrm{b}}$ & 1.34 & $\begin{array}{l}7.22 \\
58.2\end{array}$ & 1.00 & 5.00 & 0.25 & 40.00 \\
\hline $\begin{array}{c}\text { 4-ethylguaiacol } \\
152.2\end{array}$ & & $830^{\mathrm{b}}$ & 2.38 & $\begin{array}{l}3.02 \\
19.85\end{array}$ & - & - & 0.25 & 12.20 \\
\hline
\end{tabular}


Table 1. Continued

\begin{tabular}{|c|c|c|c|c|c|c|c|c|}
\hline \multirow{3}{*}{$\begin{array}{c}\text { Ligand } \\
\mathrm{MW}\left(\mathrm{g} \cdot \mathrm{mol}^{-1}\right)\end{array}$} & \multirow[t]{3}{*}{ Structure } & \multirow[t]{3}{*}{$\mathrm{K}_{\mathrm{B}}\left(\mathrm{M}^{-1}\right)$} & \multirow[t]{3}{*}{$\log \mathrm{P}^{1}$} & \multirow{3}{*}{$\begin{array}{c}S^{g} \\
g . L^{-1} \\
m M^{*}\end{array}$} & \multicolumn{4}{|c|}{ Concentrations (mM) } \\
\hline & & & & & \multicolumn{2}{|c|}{ NMR } & \multicolumn{2}{|c|}{ FT-IR } \\
\hline & & & & & BLG & Ligand & BLG & Ligand \\
\hline $\begin{array}{l}\text { eugenol } \\
164.2\end{array}$ & & $1360^{\mathrm{b}}$ & 2.73 & $\begin{array}{l}0.75 \\
5.96\end{array}$ & 0.48 & 0.48 & 0.25 & 7.30 \\
\hline $\begin{array}{l}\text { ethylvanillin } \\
166.18\end{array}$ & & $475^{b}$ & 1.55 & $\begin{array}{l}2.86 \\
17.25\end{array}$ & - & - & 0.25 & 21.10 \\
\hline $\begin{array}{l}\text { retinol } \\
286.5\end{array}$ & & $15000^{\mathrm{d}}$ & 7.62 & $\begin{array}{c}0.8810^{-3} \\
0.003\end{array}$ & - & - & 0.25 & 0.25 \\
\hline $\begin{array}{l}\text { tetradecanoic acid } \\
228.4\end{array}$ & & - & 5.98 & $\begin{array}{l}1.10^{-3} \\
0.004\end{array}$ & - & - & 0.25 & 0.25 \\
\hline $\begin{array}{c}\text { 2-isopropyl-3- } \\
\text { methoxypyrazine } \\
152.2\end{array}$ & & $452^{b}$ & 2.37 & $\begin{array}{c}0.69 \\
4.6\end{array}$ & - & - & 0.25 & 8.90 \\
\hline
\end{tabular}

${ }^{a}$ was obtained by affinity chromatography at $\mathrm{pH} 3.0(15) .{ }^{\mathrm{b}}$ was obtained by affinity chromatography at $\mathrm{pH} 3.0(16) .{ }^{\mathrm{c}}$ was obtained by affinity chromatography at $\mathrm{pH} 3.0$ (27). ${ }^{d}$ was obtained by equilibrium dialysis at $\mathrm{pH} 7.2$ (36). ${ }^{\text {e }}$ Value was estimated using the relationship of Sostmann and Guichard (27). ${ }^{f}$ Value was estimated by using EPI Suite 3.20 software. ${ }^{9}$ Solubility in water at $25^{\circ} \mathrm{C}$ was estimated from EPI Suite 3.20 software. ${ }^{*}$ Solubility was calculated in $\mathrm{mM}$ from values in $\mathrm{g} \mathrm{L}^{-1}$.

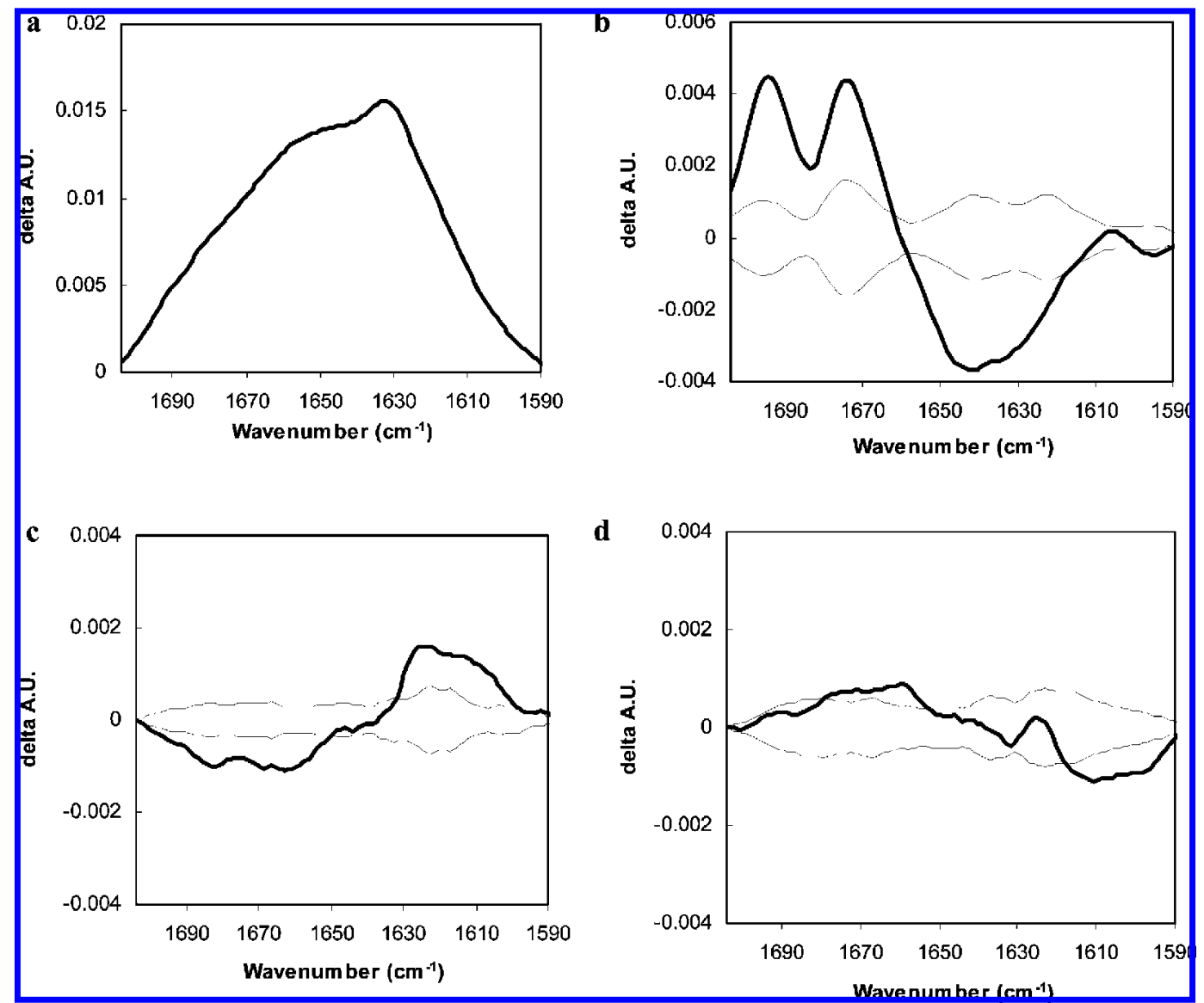

Figure 2. (a) Spectrum of amide I band of $250 \mu \mathrm{M} \mathrm{BLG}$ in $5 \%$ ethanol/50 mM phosphate buffer, $\mathrm{pH} 2.0$, and differential spectra (bold lines) representing the changes in the amide I region of BLG induced by the presence of (b) $\beta$-ionone, (c) isoamyl acetate, and (d) ethyl pentanoate, with the standard deviations in thin lines.

compound resulted in 16 differential spectra). A PCA was performed using the StatBox software (Grimmer Logiciels, Paris, France) on the data from differential spectra in the amide I band of protein (variables) obtained for the 27 ligands listed in Table 1 (individual ligand).
2D $\left({ }^{1} \mathbf{H},{ }^{1} \mathbf{H}\right)$ TOCSY NMR Experiments. The samples in solvent $\mathrm{B}$ were used for NMR analyses. Deuterium oxide $\left(\mathrm{D}_{2} \mathrm{O}\right)$ was added to solutions for the NMR field-frequency lock. Under highly acidic $\mathrm{pH}$ with low salt content, the $1 \mathrm{D}{ }^{1} \mathrm{H}$ NMR spectra (data not shown) of the 
protein solutions showed a large dispersion of chemical shifts with very intense and sharp resonances typical of a globular protein essentially in its monomeric form (4). These spectral characteristics were identical in the presence of one aroma compound, indicating no significant protein aggregation induced by ligand binding. Assignment of the protein amino acids for the solutions of BLG alone or in the presence of one aroma compound was achieved from 2D NMR TOCSYWatergate spectra of solutions in $90 \% \mathrm{H}_{2} \mathrm{O} / 10 \% \mathrm{D}_{2} \mathrm{O}(\mathrm{v} / \mathrm{v})$. All NMR spectra were recorded at $37{ }^{\circ} \mathrm{C}$ on a Bruker Avance DRX $500 \mathrm{MHz}$ NMR spectrometer, operating at $500.13 \mathrm{MHz}$ and equipped with a 5 mm z-gradient probe. $\left({ }^{1} \mathrm{H},{ }^{1} \mathrm{H}\right)$ TOCSY spectra were registered in the States-TPPI mode with water presaturation during relaxation delay to suppress the strong solvent signal. Spectra were registered with $32-88$ transients, a $1 \mathrm{~s}$ recycle delay, a spectral width of $8400 \mathrm{~Hz}$ in the two dimensions, a 40 ms mixing time, and 2048 data points in F2 and 512 increment in $\mathrm{F} 1$ dimension.

NMR spectra of the protein alone and of the protein/aroma compound solutions were recorded under identical conditions. NMR spectra were acquired and processed with Bruker XwinNMR 3.5 and Topspin 1.3 software.

\section{RESULTS}

BLG-Aroma Compound Interaction by FT-IR. The repeatability of the FT-IR method was tested and demonstrated for two aroma compounds in three different solutions. As the presence of ethanol is known to affect FT-IR spectra of BLG (29), we checked by 2D NMR experiments that $5 \%$ of ethanol in solution had no impact on the binding of $\alpha$-ionone. In fact, in the presence or absence of ethanol, similar protein residues were affected by the addition of one aroma compound (data not shown).

Differential spectra in the amide I band of protein (1700-1590 $\mathrm{cm}^{-1}$ ) were established for all of the ligands listed in Table $\mathbf{1 .}$ The differential spectra representing the changes in the amide I region of BLG induced by the presence of $\beta$-ionone, isoamyl acetate, and ethyl pentanoate are shown in Figure 2, panels b, $\mathbf{c}$, and $\mathbf{d}$, respectively. Although minor, some significant changes with regard to the standard deviations are observed.

To have a global representation of the effects induced by all of the aroma compounds, a PCA was carried out from the differential spectra obtained with all of the ligands. The two principal axes of the PCA provided $84.3 \%$ of the total information, $54.5 \%$ for axis 1 and $29.8 \%$ for axis 2 (Figure 3a). The aroma compounds are well distributed in the principal plane of PCA, suggesting the existence of changes in different regions of the amide I band of the protein depending on the ligand. Aroma compounds seem to be discriminated as a function of their chemical class. The ligands belonging to the chemical class of oxygenated terpenes (linalool, nerol, carveol, and carvone), except $\alpha$-menthone, are located in the negative part of axes 1 and 2, pointing out similar behaviors. The ligands belonging to the chemical class of ethylphenols (ethylvanillin, 4-ethylphenol, and 4-ethylguaiacol) are well separated from the other aroma compounds and located in the positive part of axes 1 and 2 with a high contribution. On the contrary, the phenolic compounds ( $p$-cresol, guaiacol, and eugenol) are located in the opposite part of the plane with a lower contribution. Within the ketone group, axis 2 discriminates $\alpha$ - and $\beta$-ionones, on the negative part, from methyl ketones (2-hexanone, 2-heptanone, 2-octanone, 2-nonanone, and 2-undecanone) on the positive part. Retinol has structural analogies with the ionones for the cyclic part and with methyl ketones for the hydrophobic chain. It is located close to the methyl ketone group. We can see that the contribution of methyl ketones along axis 2 increases with an increased chain length. Ethyl esters (ethyl butanoate, ethyl pentanoate, ethyl hexanoate, and ethyl heptanoate) are separated also along axis 2 , but contrary to methyl ketones, the increase of chain length induces a decrease of their contribution to this axis.

The loading plots in Figure $\mathbf{3 b}$ allow the interpretation of the two axes of PCA considering the wavenumbers. The shape of the first principal component (PC1) is characterized by a positive feature with a plateau between 1695 and $1665 \mathrm{~cm}^{-1}$ and a negative feature with the highest changes in the range of $1640-1610 \mathrm{~cm}^{-1}$. The assignment of the bands was done from the data obtained for BLG variant $\mathrm{A}$ in $\mathrm{H}_{2} \mathrm{O}$ solution by Dong et al. (30). Thus, PC1 may display the contribution of protein loops (1661 and $1683 \mathrm{~cm}^{-1}$ ) and $\beta$ strands (1628 and 1692 $\mathrm{cm}^{-1}$ ) in the ligand binding. The second principal component (PC2) may indicate also the contribution of protein loops (1661 $\left.\mathrm{cm}^{-1}\right)$ and $\beta$ strands $\left(1641 \mathrm{~cm}^{-1}\right)$ and points out the contribution of protein $\alpha$ helix $\left(1656 \mathrm{~cm}^{-1}\right)$ as suggested by the main positive feature between 1660 and $1630 \mathrm{~cm}^{-1}$ with a maximum at 1654 $\mathrm{cm}^{-1}$. Despite the suggested contribution of $\beta$ strands, loops, and/or $\alpha$ helix, it is not possible to assign precisely which $\beta$ strands or loops are involved in binding. Thus, FT-IR solely gives a general trend of changes induced by the presence of one aroma compound.

However, some contributions affecting the PCA results cannot be explained in regard to changes of BLG spectrum. In fact, no structural component was assigned by the literature in the range inferior to $1628 \mathrm{~cm}^{-1}$ of the BLG amide I band (30). However, the differential spectra induced by isoamyl acetate and ethyl pentanoate (Figure 2c,d), for example, show significant contributions in this range of wavelengths but with opposite signs, which could explain the opposite positions of isoamyl acetate and ethyl pentanoate in the PCA plot. The same observation was made for 2-nonanone and $\gamma$-decalactone (data not shown).

Amino Acid Assignment of BLG from 2D NMR Spectra. Figure 4 shows the $\left({ }^{1} \mathrm{H},{ }^{1} \mathrm{H}\right)$ TOCSY spectrum of BLG in the $\mathrm{NH}-\mathrm{CH}_{\alpha}$ region, which is considered to be a fingerprint of the protein amino acid sequence. This region depicts the cross-peaks due to coupling between amide proton, $\mathrm{NH}$, in the $\delta 6.5-10$ range and $\mathrm{C}_{\alpha}$-bonded protons, $\mathrm{CH}_{\alpha}$, in the $\delta 3.2-6.7$ range. We were able to assign 140 amino acids from the 162 ones previously determined by Uhrinova et al. (31). Each amino acid was characterized by a pair of chemical shifts, $\delta\left(\mathrm{NH}, \mathrm{CH}_{\alpha}\right)$, reflecting the protein fingerprint in a given dynamic state. BLG in solution undergoes arrangements into its tertiary structure indeed. This was shown for BLG A at $\mathrm{pH}$ 2.6, for which 21 possible structures diverging from mobile fragments were calculated (5).

From several solutions of $1 \mathrm{mM}$ BLG, spectra were well superimposable on the $\mathrm{NH}-\mathrm{CH}_{\alpha}$ region, and the chemical shifts of most of the residues were assigned with a deviation equal to \pm 0.014 ppm determining our experimental error. However, for some residues, significant chemical shift changes were observed. For instance, NH chemical shifts of Lys101 and Tyr102 were influenced markedly by the medium as previously shown at $\mathrm{pH} 2$ (3). Thus, these residues identified as sensitive to the medium were not taken into account for the ligand-binding experiments.

BLG-Aroma Compound Interaction by NMR: BLG Amino Acid Perturbations upon Aroma Compound Addition. The mode of ligand binding to BLG was investigated for 10 aroma compounds from different chemical classes and shapes (Table 1). Amino acid chemical shifts of protein solutions with aroma compound were compared to those of the corresponding BLG solution to highlight any significant chemical shift change, $\Delta \delta\left(\mathrm{NH}, \mathrm{CH}_{\alpha}\right)>0.014 \mathrm{ppm}$, due to the presence of one aroma compound. 


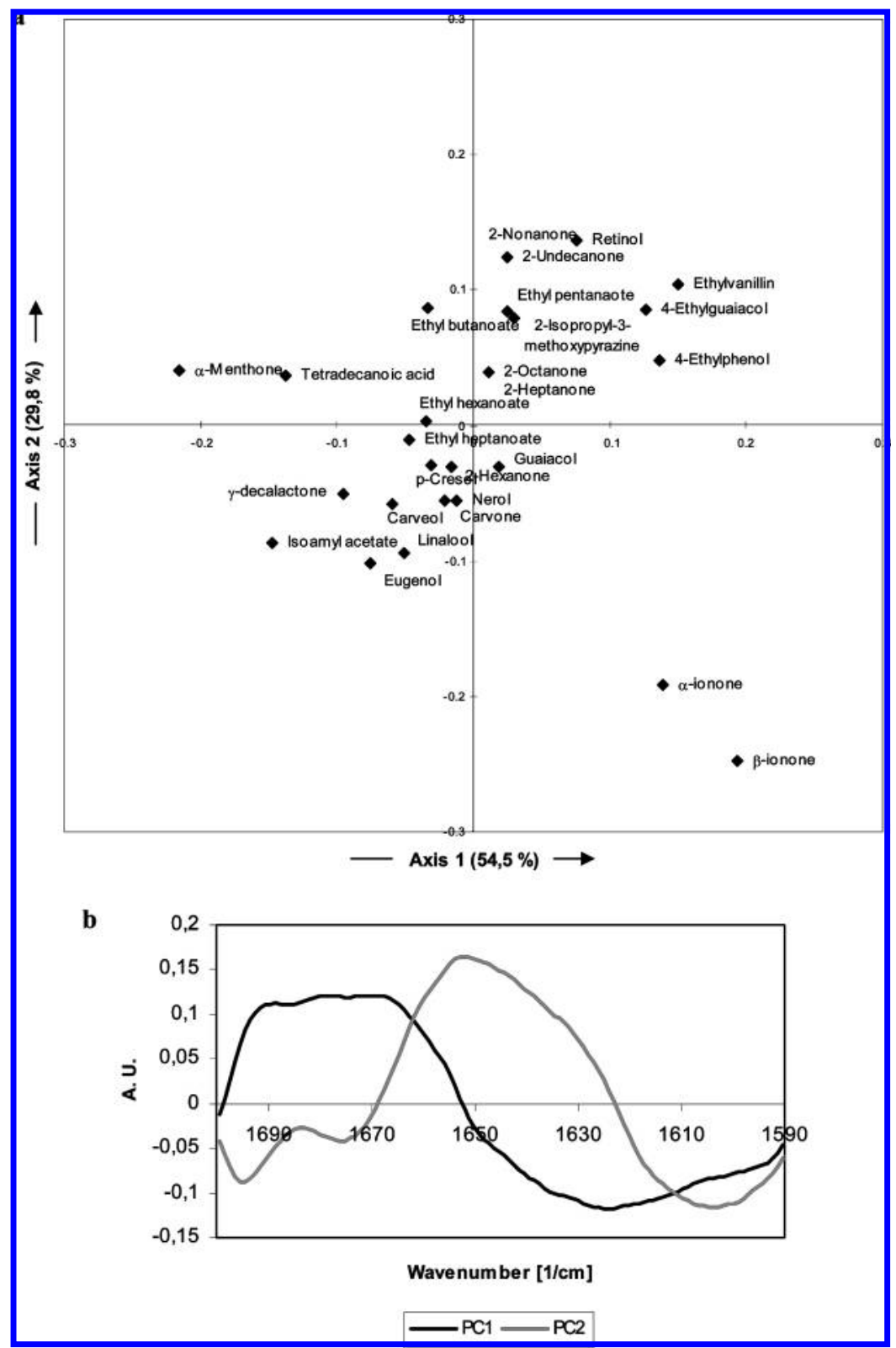

Figure 3. (a) Principal component analysis of FT-IR spectra and (b) spectral patterns corresponding to principal components (PC) 1 and 2.

Panels $\mathbf{a}$ and $\mathbf{b}$ of Figure $\mathbf{5}$ show the significant chemical shift changes of protein amino acids induced by $\gamma$-decalactone added to BLG solution at two different protein/ligand molar ratios. Significant $\mathrm{NH}$ or $\mathrm{CH}_{\alpha}$ chemical shift changes were observed for all amino acids at 1:2 molar ratio (Figure 5a), whereas only a few amino acids were affected at 1:1 molar ratio (Figure 5b). Nevertheless, the residues undergoing the strongest changes at the highest molar ratio matched the ones still perturbed for the equimolar solution. This matching concerns the same residues or adjacent ones. A saturation of BLG binding sites may occur when an excess of aroma compound was used. Hence, the strongest perturbations at 1:2 molar ratio and those that persist at 1:1 molar ratio were taken into account only to reflect the primary binding site. The same observation was made with 2-nonanone (data not shown).

From residues the most affected by the presence of $\gamma$-decalactone, three regions are drawn on the BLG 3D structure: (i) the entrance of the calyx with Gln68, Lys70, Ile71, Ile72, Ala73, and Glu74 belonging to the strand $\beta$-D; (ii) the buried cluster with Trp19, Val43, Leu46, Ile56, Ala73, Leu103, and Phe105; and (iii) the outer surface with Glu108 (strand $\beta$-G), Glu114 and $\mathrm{Gln} 115$ (loop GH), Leu117 and Val123 (strand $\beta$-H), Val128 (loop H $\alpha$ ), and Leu133 and Asp138 ( $\alpha$ helix). The same regions underwent major chemical shift changes in the presence of 2-nonanone. Moreover, $\gamma$-decalactone and 2-nonanone induced strong perturbations of Met107 pointing into the calyx. Additionally, the presence of $\gamma$-decalactone affected also the amino acid residue Asp85, which belongs to loop EF. Our results showed that $\gamma$-decalactone and 2-nonanone may interact both within the central cavity and onto the protein surface between the calyx and $\alpha$ helix. No primary binding site was evidenced under our experimental conditions.

Panels $\mathbf{c}$ and $\mathbf{d}$ of Figure $\mathbf{5}$ show the significant $\mathrm{NH}$ and $\mathrm{CH}_{\alpha}$ chemical shift changes of protein amino acids upon addition of isoamyl acetate and ethyl pentanoate, respectively. As observed for 2-nonanone and $\gamma$-decalactone, the presence of these ligands affected the whole BLG backbone residues. Thus, we took into account only the highest chemical shift changes to center the discussion on the primary binding sites. On the one hand, binding within the central cavity was evidenced by the involvement of the calyx entrance with the perturbation of Lys70, and residues around Ile71, Ile72, and Ala73, and the buried cluster 


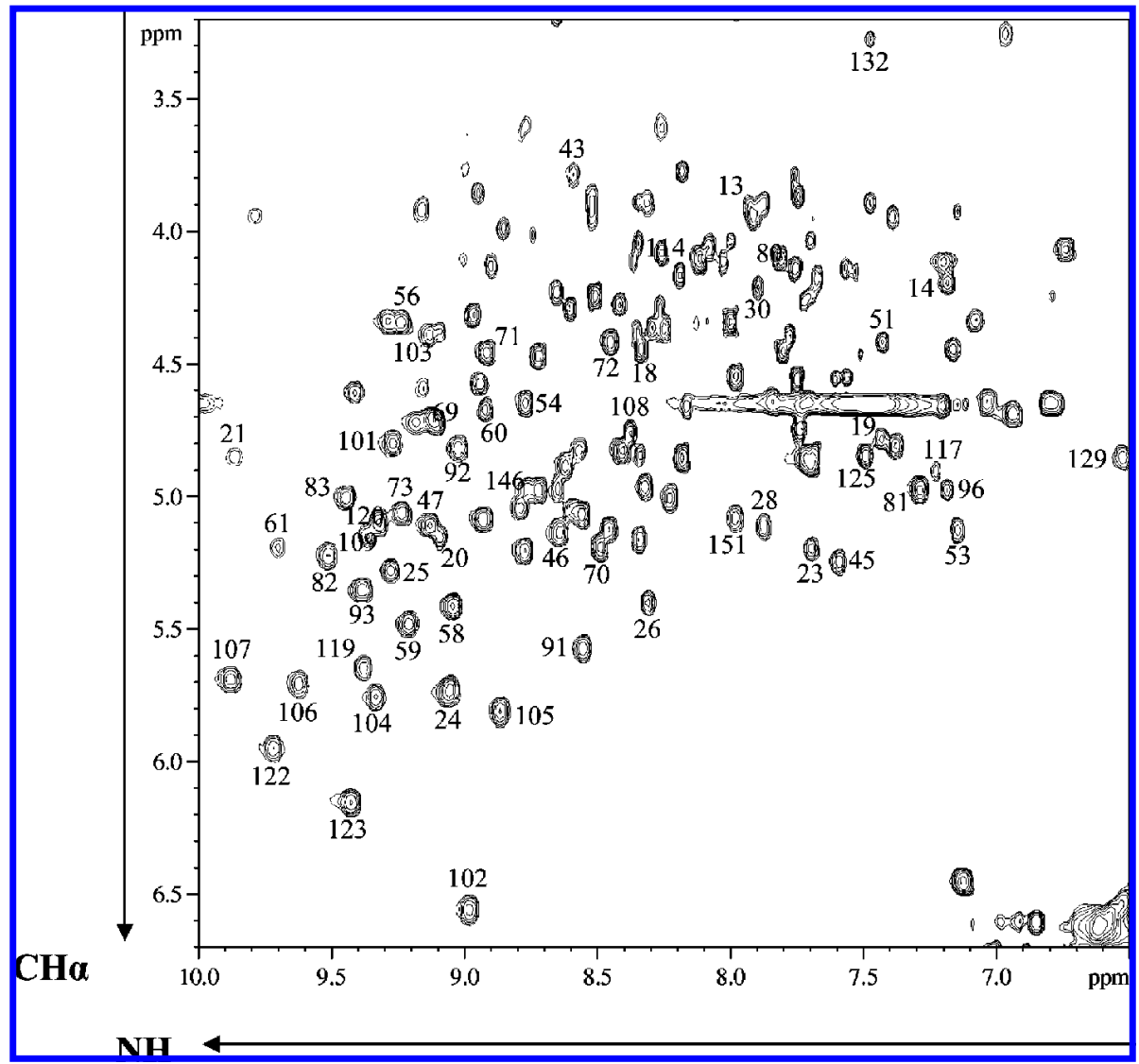

Figure 4. $\mathrm{NH}-\mathrm{CH}_{\alpha}$ region of the $\left({ }^{1} \mathrm{H},{ }^{1} \mathrm{H}\right)$ TOCSY-Watergate spectrum of $1 \mathrm{mM} \mathrm{BLG}$ in $12 \mathrm{mM} \mathrm{NaCl}, \mathrm{pH} 2.34, \mathrm{H}_{2} \mathrm{O} / \mathrm{D}_{2} \mathrm{O} 90 \% / 10 \%$ v/v at $37{ }^{\circ} \mathrm{C}$. Only the residues of interest are labeled.

with perturbation of residues centered on Trp19 (Val43, Leu46, Ile56, Ala73, Leu103, and Phe105). On the other hand, binding of isoamyl acetate and ethyl pentanoate onto the protein surface was highlighted by the perturbation of residues between the calyx and $\alpha$ helix. Perturbations of Glu108, Leu117, and Cys121 were induced by the presence of isoamyl acetate, and residues Glu108, Val123, Thr125, Met145, and Ser150 were affected by the addition of ethyl pentanoate. For the two ligands, the loop EF seemed to be affected by the binding because chemical shift changes of Asp85 were observed. Under our experimental conditions, we cannot identify the central cavity or the external site as the primary binding site.

Panels e and $\mathbf{f}$ of Figure 5 show the significant $\mathrm{NH}$ and $\mathrm{CH}_{\alpha}$ chemical shift changes of protein amino acids upon addition of $\beta$-ionone and eugenol, respectively. The presence of $\beta$-ionone induced significant NH variations of Gln13, Thr18, Ser30, Glu51, Ala80, Glu114, Asp129, Ala132, and His146. The residues Ser30 (loop AB), Glu114 (loop GH), Asp129 ( $\alpha$ helix), Ala132 ( $\alpha$ helix), and His 146 (strand $\beta$-I) draw a binding site between the calyx and $\alpha$ helix of BLG. The binding of $\beta$-ionone onto the protein surface is consistent with previous 2D NMR study (32). In addition, NH chemical shift changes of seven residues (Glu13, Lys14, Ser30, Glu51, Ala80, Asp129, and Ala132) were induced upon addition of eugenol. Among them, six were affected also by the presence of $\beta$-ionone. Under our experimental conditions, an external site was evidenced as the primary binding site for $\beta$-ionone and eugenol. The perturbations shared by $\beta$-ionone and eugenol are similar in sign and size, reinforcing the hypothesis of similar binding behaviors for these two ligands.

BLG-aroma compound solutions with $\alpha$-ionone, linalool, guaiacol, and carvone were investigated also (data not shown).
No change of $\mathrm{NH}$ and $\mathrm{CH}_{\alpha}$ chemical shifts was observed upon addition of $\alpha$-ionone in the studied conditions. Very few perturbations were induced by the presence of linalool, guaiacol, and carvone under our experimental conditions. The perturbations of residues at the entrance of the calyx for linalool (Lys70 and Ile72) and guaiacol (Gln59, Gln68, and Ile72) suggest a primary binding site within the central cavity. The perturbations observed for carvone would indicate a binding within the central cavity (Ile72 and Val92) and also onto the protein surface with chemical shift changes of Glu108 (strand $\beta$-G), Asp129 ( $\alpha$ helix), and Gln 155 .

\section{DISCUSSION}

The FT-IR and NMR data provide different but complementary information on BLG-aroma compound interactions. FTIR experiments highlight spectral changes of BLG amide I band due to the presence of aroma compounds and allowed us a screening among a wide range of ligands (terpenes, phenols, ketones, and esters). Although FT-IR experiments suggest different spectral changes depending on the added ligand, this method is not suitable to assign a binding site location. This is due mainly to a lack of precision in the assignment of the protein structure. To determine ligands binding sites on BLG, our 2D NMR study was performed on 10 aroma compounds of interest. Among them, the addition of 8 showed a significant effect on protein IR spectrum, whereas the 2 others, guaiacol and carvone, induced no significant change of protein amide I band (position in the middle of PCA plot).

The aim of the present discussion is not to compare the results from the point of view of ligands themselves. It is made rather to get complementary data and formulate general features that 


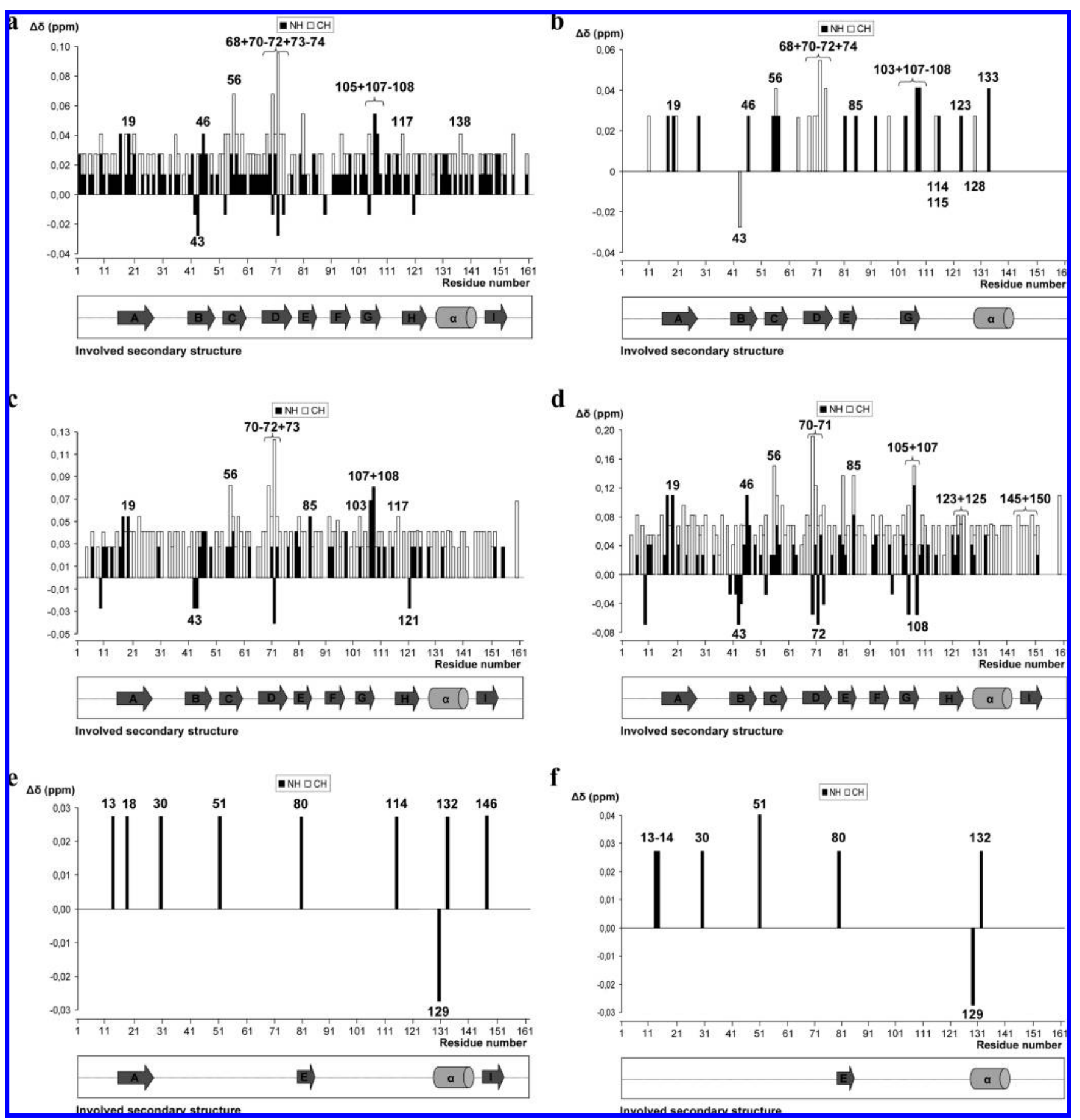

Figure 5. Significant chemical shift variations of $\mathrm{BLG} \mathrm{NH}$ and $\mathrm{CH}_{\alpha}$ protons upon addition of aroma compound: (a) BLG/ $\gamma$-decalactone solution 1:2; (b) BLG/ $\gamma$-decalactone solution 1:1; (c) BLG/isoamyl acetate solution 1:10; (d) BLG/ethyl pentanoate solution 1:10; (e) BLG/ $\beta$-ionone solution 1:1; (f) BLG/ eugenol solution 1:1. Only the residues of interest are shown. Secondary structure involved in binding is shown at the bottom of each graph.

can be helpful for a better understanding of the retention/release of aroma compounds from foods containing proteins.

In regard to the PCA from FT-IR data (Figure 3a), the distribution of ligands in the principal plane suggests different behaviors as a function of chemical class. Surely, the PCA shows discriminations between ethyl phenols, methyl ketones, ethyl esters, and terpenes. The effect observed within a chemical class for methyl ketones and ethyl esters depends also on the chain length, consistent with hydrophobic interactions as suggested previously by Pelletier et al. (15). However, for the ligands belonging to different chemical classes, NMR spectroscopy revealed no link between the hydrophobicity of the aroma compounds and their binding site(s). Obviously, the presence of $\beta$-ionone $(\log P=4.42)$ and eugenol $(\log P=2.73)$ affected the chemical shifts of similar BLG residues, although their hydrophobicity values are very different (Table 1).

Upon addition of 1 of the 10 selected aroma compounds, the 2D NMR data evidenced at least the two binding sites on BLG, the central cavity and one external site as described in literature (Figure 1). The residues affected by the addition of one aroma compound draw one or two binding sites on BLG 3D structure as a function of the ligand. On the one hand, the location of one aroma compound within the central cavity involved strongly strands $\beta$-C and $\beta$-D with the highest perturbations for residues Lys70, Ile71, Ile72, and Glu74. Thus, the residues located at the entrance of the calyx may control ligand access to the central 
cavity as suggested by other works (18-20, 24). In addition, NMR data highlighted perturbations of Trp19 and several residues around it belonging to the hydrophobic buried cluster identified at $\mathrm{pH} 2$ by Ragona et al. (6). Moreover, as previously displayed for the accommodation of retinol and palmitate $(20,25)$, the residue Met107 pointing toward the interior of protein is affected by ligand binding within the central cavity. It is worth noting the behavior of loop EF (residues 85-90) of the protein, which acts as a gate over the central calyx and is in its closed conformation at $\mathrm{pH} 2.6$ (5). Although loop EF may be folded over the entrance of the calyx, the NMR data evidence binding within the central cavity of BLG. The strong perturbation of the amino acid residue Asp85 upon binding of one aroma compound within the central cavity suggests a conformational change of this gate, modulating access to the calyx and allowing the binding, which is in agreement with the literature (33). On the other hand, the location of one aroma compound onto the protein surface may occur in a site located between the calyx and $\alpha$ helix. NMR showed the perturbations of several residues belonging to the $\alpha$ helix or pointing toward the helix, indicating interactions onto the protein surface through strands $\beta-\mathrm{G}, \beta-\mathrm{H}$, and $\beta$-I. All of the highlighted residues are close to the hydrophobic surface of BLG defined by Monaco et al. (11) for retinol binding.

The NMR study suggests at least two binding behaviors with a primary binding site depending on the aroma compound added. Whereas $\gamma$-decalactone, 2-nonanone, isoamyl acetate, and ethyl pentanoate may have a similar behavior with binding in both BLG sites, the external site was evidenced as the primary binding site for $\beta$-ionone and eugenol under our experimental conditions. Additionally, no primary site was highlighted for linalool, guaiacol, and carvone as very few perturbations of protein amino acids were observed. The particular behavior of $\beta$-ionone and eugenol was suggested also by FT-IR because these ligands are the only ones having a significant contribution on axis $3(8.3 \%)$ of the PCA (data not shown). Concerning guaiacol and carvone, investigated by FT-IR with an even greater excess of aroma compound, they had a low impact on the structural components of BLG amide I band.

Contrary to the FT-IR data, NMR did not evidence the binding between BLG and $\alpha$-ionone. The binding of $\alpha$-ionone has been also controversial in the literature. No binding was monitored for BLG variant B at pH 3.0 using fluorescence (22), and only at $\mathrm{pH} 9.0$ for the mixture $\mathrm{AB}$ by a diffusion-based NOE method between pH 3.0 and 11.0 (34). However, $\alpha$-ionone was found to interact with BLG variant $\mathrm{A}$ at $\mathrm{pH} 2.0$ using infrared spectroscopy (28), with variants $\mathrm{A}, \mathrm{B}$, and $\mathrm{AB}$ at $\mathrm{pH}$ 3.0 using affinity chromatography (27), and with a mixture of $\mathrm{A}$ and $\mathrm{B}$ variants at $\mathrm{pH} 3.0-9.0$ using dynamic coupled column liquid chromatography (35).

With regard to the structures of the two ionones, the location of the ionone cycle and the isoprenoid chain in two different planes could induce a steric hindrance for $\alpha$-ionone binding. Dufour et al. suggested also that fluorescence may be unable to detect the interaction between $\alpha$-ionone and BLG because of the insufficient distance between the residue Trp-19 and the $\alpha$-ionone binding site (22). In the present study, the higher concentration of $\alpha$-ionone used for FT-IR could explain the different conclusions obtained with the two methods. To determine the binding site(s) for $\alpha$-ionone, it should be necessary to increase its concentration, which was not possible in the solvent used for NMR experiments.

From NMR data and looking at the structure of aroma compounds, the central cavity may accommodate easily the elongated structures, whereas the external site may fit the compact structures preferentially. FT-IR data tend also to show different binding behaviors between the elongated and compact structures. In fact, PCA discriminated methyl ketones from $\alpha-$ and $\beta$-ionones. Considering the binding behaviours displayed by NMR for $\gamma$-decalactone, 2-nonanone, isoamyl acetate, and ethyl pentanoate, the presence of a flexible acyl chain may allow the ligand to bind to both sites. Other works showed that ligands with a long and flexible chain such as palmitate bind within the central cavity (20) or onto the outer surface (19). Ligands with a long acyl chain may fold to adopt a more compact structure and fit in the external site. The position of 2-hexanone, 2-heptanone, 2-octanone, ethyl hexanoate, and ethyl heptanoate in the middle of the PCA plot may suggest that the flexibility of these ligands requires less arrangement of BLG structure to make room for their accommodation.

In conclusion, the present study shows that aroma compound binding to BLG can be evidenced by protein spectral changes through amide I band or amino acid chemical shifts from FTIR and NMR investigations, respectively. The combined data point out that the chemical class, the hydrophobicity, and the structure of aroma compounds influence the ligand binding. Under our experimental conditions, at least two binding behaviors were suggested as a function of aroma compounds. 2D NMR spectroscopy allowed the location of the two binding sites for BLG in its monomeric form, that is, the central cavity and an external site onto the protein surface. The NMR data displayed the binding specificity of 10 selected ligands indicating that their structure directs the aroma compound onto a primary binding site. The central cavity, to which access may be controlled by the protein residues located at the entrance of the calyx, accommodates the ligands with an elongated structure. The binding of aroma compound onto the protein surface occurs in a site located between strand $\beta-\mathrm{G}, \alpha$ helix, and strand $\beta$-I. The external site fits the ligands that have or can adopt a compact structure by folding.

The present study gives new insights into the binding mechanisms of the native BLG, furthering our understanding of retention/release mechanisms of aroma compounds in dairy foods. Moreover, BLG can undergo structural modifications during the dairy process. To complete our data, additional studies are in progress to investigate the impact of a modification of the protein conformation, due to heat denaturation, for instance, on ligand binding.

\section{ABBREVIATIONS USED}

2D, two-dimensional; BLG, $\beta$-lactoglobulin; FT-IR, Fourier transform infrared; NMR, nuclear magnetic resonance; NOE, nuclear Overhauser effect; PC, principal component; PCA, principal component analysis.

\section{LITERATURE CITED}

(1) Guichard, E. Interactions between flavor compounds and food ingredients and their influence on flavor perception. Food Rev. Int. 2002, 18 (1), 49-70.

(2) Sawyer, L. $\beta$-Lactoglobulin. In Advanced Dairy Chemistry Vol. 1: Proteins, 3rd ed.; Fox, P. F., McSweeney, P. L. H., Eds.; Kluwer Academic/Plenum: New York, 2003; Vol. 1, pp 319386.

(3) Fogolari, F.; Ragona, L.; Zetta, L.; Romagnoli, S.; De Kruif, K. G.; Molinari, $\mathrm{H}$. Monomeric bovine $\beta$-lactoglobulin adopts a $\beta$-barrel fold at $\mathrm{pH}$ 2. FEBS Lett. 1998, 436 (2), 149-154.

(4) Molinari, H.; Ragona, L.; Varani, L.; Musco, G.; Consonni, R.; Zetta, L.; Monaco, H. L. Partially folded structure of monomeric bovine $\beta$-lactoglobulin. FEBS Lett. 1996, 381 (3), 237-243. 
(5) Uhrinova, S.; Smith, M. H.; Jameson, G. B.; Uhrin, D.; Sawyer, L.; Barlow, P. N. Structural changes accompanying $\mathrm{pH}$-induced dissociation of the $\beta$-lactoglobulin dimer. Biochemistry 2000, 39, $3565-3574$.

(6) Ragona, L.; Pusterla, F.; Zetta, L.; Monaco, H. L.; Molinari, H. Identification of a conserved hydrophobic cluster in partially folded bovine $\beta$-lactoglobulin at $\mathrm{pH}$ 2. Fold. Des. 1997, 2 (5), 281-290.

(7) Brownlow, S.; Morais Cabral, J. H.; Cooper, R.; Flower, D. R.; Yewdall, S. J.; Polijarpov, I.; North, A.; Sawyer, L. Bovine $\beta$-lactoglobulin at $1.8 \AA$ resolution-still an enigmatic lipocalin. Structure 1997, 5 (4), 481-495.

(8) Qin, B. Y.; Bewley, M. C.; Creamer, L. K.; Baker, E. N.; Jameson, G. B. Functional implications of structural differences between variants A and B of bovine $\beta$-lactoglobulin. Protein Sci. 1999, 8 , 75-83.

(9) Qin, B. Y.; Bewley, M. C.; Creamer, L. K.; Baker, H. M.; Baker, E. N.; Jameson, G. B. Structural basis of the Tanford transition of bovine $\beta$-lactoglobulin. Biochemistrv 1998, 37, 14014-14023.

(10) Jameson, G. B.; Adams, J. J.; Creamer, L. K. Flexibility, functionality and hydrophobicity of bovine $\beta$-lactoglobulin. Int. Dairv J. 2002, 12 (4), 319-329.

(11) Monaco, H. L.; Zanotti, G.; Spadon, P.; Bolognesi, M.; Sawyer, L.; Eliopoulos, E. E. Crystal structure of the trigonal form of bovine $\beta$-lactoglobulin and of its complex with retinol at $2.5 \AA$ resolution. J. Mol. Biol. 1987, 197, 695-706.

(12) Guichard, E.; Langourieux, S. Interactions between $\beta$-lactoglobulin and flavour compounds. Food Chem. 2000, 71, 301-308.

(13) Andriot, I.; Harrison, M.; Fournier, N.; Guichard, E. Interactions between methyl ketones and $\beta$-lactoglobulin: sensory analysis, headspace analysis, and mathematical modeling. J. Agric. Food Chem. 2000, 48, 4246-4251.

(14) Jouenne, E.; Crouzet, J. Effect of $\mathrm{pH}$ on retention of aroma compounds by $\beta$-lactoglobulin. J. Agric. Food Chem. 2000, 48, 1273-1277.

(15) Pelletier, E.; Sostmann, K.; Guichard, E. Measurement of interactions between $\beta$-lactoglobulin and flavor compounds (esters, acids, and pyrazines) by affinity and exclusion size chromatography. $J$. Agric. Food Chem. 1998, 46, 1506-1509.

(16) Reiners, J.; Nicklaus, S.; Guichard, E. Interactions between $\beta$-lactoglobulin and flavour compounds of different chemical classes. Impact of the protein on the odour perception of vanillin and eugenol. Lait 2000, 80, 347-360.

(17) Van Ruth, S. M.; Villeneuve, E. Influence of $\beta$-lactoglobulin, $\mathrm{pH}$ and presence of other aroma compounds on the air/liquid partition coefficients of 20 aroma compounds varying in functional group and chain length. Food Chem. 2002, 79 (2), 157-164.

(18) Cho, Y.; Batt, C. A.; Sawyer, L. Proding the retinol-binding site of bovine $\beta$-lactoglobulin. J. Biol. Chem. 1994, 269 (15), 11102 11107.

(19) Sawyer, L.; Brownlow, S.; Polikarpov, I.; Wu, S. Y. $\beta$-Lactoglobulin: structural studies, biological clues. Int. Dairv J. 1998, 8 , $65-72$.

(20) Wu, S. Y.; Pérez, M. D.; Puyol, P.; Sawyer, L. $\beta$-Lactoglobulin binds palmitate within its central cavity. J. Biol. Chem. 1999, 274 (1), 170-174.

(21) Muresan, S.; van der Bent, A.; de Wolf, F. A. Interaction of $\beta$-lactoglobulin with small hydrophobic ligands as monitored by fluorimetry and equilibrium dialysis: nonlinear quenching effect related to protein-protein association. J. Agric. Food Chem. 2001, 49, 2609-2618.

(22) Dufour, E.; Haertlé, T. Binding affinities of $\beta$-ionone and related flavor compounds to $\beta$-lactoglobulin: effects of chemical modifications. J. Agric. Food Chem. 1990, 38, 1691-1695.
(23) Ragona, L.; Fogolari, F.; Zetta, L.; Puyol, P.; De Kruif, K.; Löhr, F.; Rüterjans, H.; Molinari, H. Bovine $\beta$-lactoglobulin: interactions studies with palmitic acid. Protein Sci. 2000, 9, 1347-1356.

(24) Lange, D. C.; Kothari, R.; Patel, R. C.; Patel, S. C. Retinol and retinoic acid bind to a surface cleft in bovine $\beta$-lactoglobulin: a method of binding site determination using fluorescence resonance energy transfer. Biophys. Chem. 1998, 74, 45-51.

(25) Kontopidis, G.; Holt, C.; Sawyer, L. The ligand-binding site of bovine $\beta$-lactoglobulin: evidence for a function. J. Mol. Biol. 2002, 318 (4), 1043-1055.

(26) Yang, J.; Powers, J. R.; Clark, S.; Dunker, A. K.; Swanson, B. G. Hydrophobic probe binding of $\beta$-lactoglobulin in the native and molten globule state induced by high pressure as affected by $\mathrm{pH}$, $\mathrm{KIO}_{3}$ and $N$-ethylmaleimide. J. Agric. Food Chem. 2002, 50, 5207-5214.

(27) Sostmann, K.; Guichard, E. Immobilized $\beta$-lactoglobulin on a HPLC-column: a rapid way to determine protein/flavour interactions. Food Chem. 1998, 62, 509-513.

(28) Lübke, M.; Guichard, E.; Le Quéré, J. L. In Infrared spectroscopic study of $\beta$-lactoglobulin interactions with flavor compounds Abstracts, 218th National Meeting of the American Chemical Society, New Orleans, LA, Aug 24-26, 1999; Roberts, D. D., Taylor, A. J., Eds.; American Chemical Society, Washington, DC, 2000; pp 282-292.

(29) Robert, P.; Lavenant, L.; Renard, D. Infrared two-dimensional correlation and principal component analyses applied to $\beta$-lactoglobulin aggregation in water-ethanol solution. Appl. Spectrosc. 2002, 56 (9), 1180-1185.

(30) Dong, A.; Matsuura, J.; Allison, S. D.; Chrisman, E.; Manning, M. C.; Carpenter, J. F. Infrared and circular dichroism spectroscopic characterization of structural differences between $\beta$-lactoglobulin A and B. Biochemistry 1996, 35, 1450-1457.

(31) Uhrinova, S.; Uhrin, D.; Denton, H.; Smith, M.; Sawyer, L.; Barlow, P. N. Complete assignment of ${ }^{1} \mathrm{H},{ }^{13} \mathrm{C}$ and ${ }^{15} \mathrm{~N}$ chemical shifts for bovine $\beta$-lactoglobulin: secondary structure and topology of the native state is retained in a partially unfolded form. J. Biomol. NMR 1998, 12, 89-107.

(32) Lübke, M.; Guichard, E.; Tromelin, A.; Le Quéré, J. L. Nuclear magnetic resonance spectroscopic study of $\beta$-lactoglobulin interactions with two flavor compounds, $\gamma$-decalactone and $\beta$-ionone. $\underline{J}$. Agric. Food Chem. 2002, 50, 7094-7099.

(33) Ragona, L.; Fogolari, F.; Catalano, M.; Ugolini, R.; Zetta, L.; Molinari, H. EF loop conformational change triggers ligand binding in $\beta$-lactoglobulins. J. Biol. Chem. 2003, 278, 3884038846.

(34) Jung, D.-M.; Ebeler, S. E. Investigation of binding behavior of $\alpha$ - and $\beta$-ionones to $\beta$-lactoglobulin at different $\mathrm{pH}$ values using a diffusion-based NOE pumping technique. J. Agric. Food Chem. 2003, 51, 1988-1993.

(35) Jouenne, E.; Crouzet, J. Determination of apparent binding constants for aroma compounds with $\beta$-lactoglobulin by dynamic coupled column liquid chromatography. J. Agric. Food Chem. 2000, 48, 5396-5400.

(36) Puyol, P.; Pérez, M. D.; Ena, J. M.; Calvo, M. Interaction of bovine $\beta$-lactoglobulin and other bovine and human whey proteins with retinol and fatty acids. Agric. Biol. Chem. 1991, 55 (10), 25152520 .

Received for review June 16, 2008. Revised manuscript received September 5, 2008. Accepted September 7, 2008.

JF801841U 